Introduction: Concurrent chemoradiotherapy (CTRT) remains one of the treatment options in patients with muscle invasive bladder cancer (MIBC) unwilling/unsuitable for radical surgery. We evaluated the role of volumetric modulated arc therapy (VMAT) in MIBC patients treated with definitive CTRT.

Material and methods: 25 patients of histologically proven transitional cell MIBC (T2-T4a, NO, MO) unwilling/ unsuitable for radical surgery (after maximal transurethral resection of bladder tumour) were recruited in this prospective study. Primary clinical target volume (CTV) consisted of the gross tumour and whole bladder. Primary planning target volume (PTV) and nodal PTV were prescribed $60 \mathrm{~Gy}$ and 54 Gy (both in 30 fractions). Concurrent chemotherapy was cisplatin $\left(40 \mathrm{mg} / \mathrm{m}^{2}\right)$ weekly. Acute toxicities were assessed as per Common Terminology Criteria for Adverse Events (CTCAE) version 4.0. Survival estimates were done from the date of registration using the Kaplan-Meier method. Results: Median age was 70 years (3780 years). Median overall treatment time was 45 days (44-51). Median number of chemotherapy cycles was 5 (range 3-6). 5 (20\%) and 4 (16\%) patients respectively suffered from acute grade $\geq 2$ gastrointestinal and grade $\geq 2$ genitourinary toxicities during treatment. One patient each had grade 3 anaemia and neutropenia. At a median follow-up of 34 months (10-45 months), 3-year progression-free survival and overall survival were $65.6 \%$ and $81.2 \%$ respectively. 3 -year distant metastasis-free survival was $90.5 \%$. Bladder preservation rate at 3 years was $68 \%$.

Conclusions: Definitive CTRT with VMAT is well tolerated in patients with MIBC unsuitable for surgery and yields decent survival and bladder preservation outcome.

Key words: bladder carcinoma, radiotherapy, chemotherapy, VMAT.

Contemp Oncol (Pozn) 2020; 24 (3): 177-182 DOI: https://doi.org/10.5114/wo.2020.100275

\section{Prospective evaluation of definitive chemoradiotherapy with volumetric modulated arc therapy in patients with muscle invasive carcinoma of urinary bladder}

Madhup Rastogi ${ }^{1}$, Ajeet K. Gandhi ${ }^{1}$, Ramakant Tiwari ${ }^{1}$, Sambit S. Nanda ${ }^{1}$, Satyajeet Rath ${ }^{1}$, Rohini Khurana ${ }^{1}$, Rahat Hadi ${ }^{1}$, Shantanu Sapru ${ }^{1}$, Anoop Srivastava ${ }^{1}$, Diwakar Dalela ${ }^{2}$

${ }^{1}$ Department of Radiation Oncology, Dr Ram Manohar Lohia Institute of Medical

Sciences, Lucknow, India

${ }^{2}$ Department of Urology, King George Medical University, Lucknow, India

\section{Introduction}

Bladder cancers constitute 3\% of total cancer incidence worldwide with about 0.5 million new cases being reported per year, according to GLOBOCAN 2018 [1]. Traditionally, muscle invasive bladder cancer has been treated with radical cystectomy with ileal conduit (RC) and pelvic lymph node dissection followed by adjuvant therapy depending on post-operative histopathology. However, high perioperative risks coupled with the physical and psychological impact of urinary diversion and sexual dysfunction warranted an alternative approach [2, 3].

Trimodality therapy (TMT) for bladder conservation consists of maximal transurethral resection of the bladder tumour (TURBT), radiotherapy (RT) and concurrent chemotherapy with RC being reserved as a salvage option. Historically, TMT provides bladder preservation rates of approximately $70-75 \%$ at 5 years [4] and $50-60 \%$ at 10 years $[5,6]$. Although there is a scarcity of evidence pertaining to head-on comparison of RC vis-a-vis TMT, the existing evidence favours RC in terms of locoregional control. This may be attributed to selection bias, with better performance status and younger patients being given preference for surgery over TMT. Further, the RT techniques and chemotherapeutic agents used in historical studies have evolved over time. Thus, the oncologic outcome achieved with carefully selected patients using modern RT techniques and chemotherapy may be similar to RC, and this has been demonstrated in a few metanalyses and propensity score analyses [4, 7]. The TMT approach with concurrent chemoradiotherapy (CTRT) has potentiated the tumour control rates in post-TURBT bladder cancer patients [8, 9]. In the study by James et al., the 2-year locoregional disease-free survival rate was significantly better $(p=0.03)$ in the CTRT group 67\% $(59-74 \%)$ compared to $54 \%(46-62 \%)$ in the RT group at a median follow-up of 69.9 months [9].

Traditionally, the TMT approach in bladder cancer included conventional RT leading to increased genitourinary (GU) and gastrointestinal (GI) toxicity. James et al. in the BC 2001 trial [9] reported grade 3-5 acute GU toxicity of $38 \%$ and GI toxicity of $17 \%$ with the TMT approach. Based on the dosimetric studies, intensity-modulated radiotherapy (IMRT) has been hypothesized to minimize the dose to the small and large bowel without compromising target volume coverage [10]. Literature pertaining to volumetric modulated arc therapy (VMAT) has limitations such as varied inclusion criteria, use of neoadjuvant chemotherapy [11] and being retrospective [12] in nature. 
Against this backdrop, our study was designed with the primary objective of assessing the feasibility and toxicity of VMAT with concurrent chemotherapy in muscle invasive bladder cancer patients treated with radical RT after maximal transurethral resection as a part of the TMT approach. We also intended to evaluate the efficacy of this approach in terms of bladder preservation rate and survival outcome.

\section{Material and methods}

This study was a prospective interventional cohort study conducted between August 2015 and December 2018, with the recruitment period being from August 2015 to November 2016, at a tertiary care centre with due approval from the institutional ethics committee. Patients with histopathologically confirmed, muscle invasive, transitional cell carcinoma of the bladder T2-T4, NO, MO (AJCC $7^{\text {th }}$ ) [13] after complete/maximal TURBT, age 18-80 years of either sex with Karnofsky Performance Status (KPS) scale $\geq 70$ and unifocal disease were included in the study. Patients with tumour related hydroureteronephrosis, multifocal disease, extensive carcinoma in situ or previous intravesical BCG therapy were excluded. Patients with any synchronous or metachronous malignancy, previous history of any malignancy, or unfit for concurrent cisplatin were excluded from the study. Patients were required to provide informed written consent prior to enrolment in the study. Pre-treatment evaluation included detailed history, clinical examination complete blood counts, routine biochemistry, chest X-ray, cystoscopy, contrast-enhanced computed tomography (CECT) of the abdomen and pelvis and bone scan.

\section{Computed tomography simulation}

The patients included in the study were immobilized in a supine position with knee rest and 2 sets of CT simulation were done. The patients were asked to void the

Table 1. Dose volume parameters for organs at risk and target volumes

\begin{tabular}{|c|c|c|}
\hline $\begin{array}{l}\text { Target/ } \\
\text { Organs at risk }\end{array}$ & Constraints given & Achieved doses \\
\hline Rectum & V $50<50 \%$ & $\begin{array}{l}\text { Median V50 }=30 \% \\
\text { Range V50: } 28-48 \%\end{array}$ \\
\hline $\begin{array}{l}\text { Abdominal } \\
\text { cavity }\end{array}$ & V45 < $195 c c$ & $\begin{array}{l}\text { Median V45 }=202 \mathrm{cc} \\
\text { Range V45: } 124-285 \mathrm{cc}\end{array}$ \\
\hline $\begin{array}{l}\text { Head of femur } \\
\text { right }\end{array}$ & $\mathrm{D}_{\max }<45 \mathrm{~Gy}$ & $\begin{array}{l}\text { Median } D_{\max }=43 G y \\
\text { Range } D_{\max }: 35-51 G y\end{array}$ \\
\hline $\begin{array}{l}\text { Head of femur } \\
\text { left }\end{array}$ & $\mathrm{D}_{\max }<45 \mathrm{~Gy}$ & $\begin{array}{l}\text { Median } D_{\max }=44 \mathrm{~Gy} \\
\text { Range } D_{\max }: 35-50 \mathrm{~Gy}\end{array}$ \\
\hline PTV-HR & $\begin{array}{l}60 / 30 \text { fractions at } \\
2 \text { Gy/fraction } \\
\text { D95 } \geq 95 \%\end{array}$ & $\begin{array}{c}\text { Median D95 = 57 Gy } \\
\text { Range D95 = 58.2-59.7 Gy }\end{array}$ \\
\hline PTV-IR & $\begin{array}{c}54 \text { Gy/30 fractions } \\
\text { at } 1.8 \text { Gy/fraction } \\
\text { D95 } \geq 95 \%\end{array}$ & $\begin{array}{c}\text { Median D95 = 51.8 Gy } \\
\text { Range D95 }=50.78-52.92 \text { Gy }\end{array}$ \\
\hline
\end{tabular}

urine and then drink $500 \mathrm{ml}$ of water. At 90 minutes after drinking the water, CT simulation without contrast was performed and it was deemed as a full bladder scan. Thereafter, the patient was asked to void the urine and contrast enhanced CT simulation was performed using 70-100 $\mathrm{ml}$ of non-ionic contrast on an empty bladder with knee rest and it was deemed as empty bladder scan. Images were acquired using a Multislice CT Simulator (Siemens SOMATOM) with $3 \mathrm{~mm}$ image acquisition from L1-L2 to mid-thigh. In our study, contouring was done as per the consensus guideline given by Hindson et al. [14]. Gross tumour volume (GTV) was defined as macroscopic tumour visible on $\mathrm{CT}$ and/or on cystoscopy. The primary clinical target volume (CTV-P) was contoured as GTV along with the whole bladder, identified by the outer bladder wall. CTV-P further included all anatomical variation such as cystocele and diverticulum $[14,15]$. In patient with tumours at the bladder base, the proximal urethra was also included in the CTV.

The two data sets of simulations (full bladder and empty bladder) were used to generate the internal target volume (ITV) to ensure that in all possible circumstances the ITV included the maximum extension of the full bladder. However, the CT slices with empty bladder were used as the primary image for GTV and CTV delineations. CTV nodal included internal (hypogastric and obturator), external iliac lymph nodes and presacral lymph nodes. The nodal contouring was done in accordance with Radiation Therapy Oncology Group (RTOG) nodal contouring for pelvic lymph nodes [16].

The ITV was given a $1 \mathrm{~cm}$ isotropic margin to generate the primary planning target volume (PTV-P). The PTV nodal (PTV-N) was generated by $7 \mathrm{~mm}$ uniform expansion of

Table 2. Patient characteristics

\begin{tabular}{|c|c|c|}
\hline Parameter & Number & Percentage (\%) \\
\hline Sex, male : female & \multicolumn{2}{|c|}{$24: 1$} \\
\hline Age, median (range) & \multicolumn{2}{|c|}{70 years ( $37-80$ years) } \\
\hline \multicolumn{3}{|l|}{ KPS } \\
\hline$\geq 80$ & 3 & 12 \\
\hline$<80$ & 22 & 88 \\
\hline \multicolumn{3}{|l|}{ T stage } \\
\hline $\mathrm{T} 2$ & 13 & 52 \\
\hline T3 & 7 & 28 \\
\hline $\mathrm{T} 4$ & 5 & 20 \\
\hline \multicolumn{3}{|l|}{ Overall stage } \\
\hline II & 13 & 52 \\
\hline III & 12 & 48 \\
\hline \multicolumn{3}{|c|}{ Number of concurrent chemotherapy cycles } \\
\hline$\geq 5$ & 21 & 84 \\
\hline$<5$ & 4 & 16 \\
\hline \multicolumn{3}{|l|}{ Differentiation } \\
\hline High & 19 & 76 \\
\hline Low & 6 & 24 \\
\hline
\end{tabular}

KPS - Karnofsky Performance Status scale 
CTV-N. All planning and treatment were carried out with an empty bladder to minimize the risk of geographic miss and to keep the treated volumes as small as possible. The organs at risk contoured were rectum, bilateral femoral heads, and abdominal cavity, according to RTOG pelvic normal tissue contouring guidelines by Gay et al. [17].

60 Gy in 30 fractions at 2 Gy per fraction (5 fractions per week) was delivered to PTV-P and 54 Gy in 30 fractions to PTV-N at 1.8 Gy per fraction was delivered along with concurrent cisplatin $\left(40 \mathrm{mg} / \mathrm{m}^{2}\right)$ weekly. A complete blood count, serum creatinine and electrolytes were drawn at the start of every week.

Volumetric modulated arc therapy (VMAT) plans were generated using TPS-CMS Monaco (Version 5.0) with an intention to cover at least $95 \%$ of the PTV by the $95 \%$ isodose line. Planning dose constraints are enumerated in Table 1. Treatment was delivered on a multi-energy (6-10-15 MV) ELEKTA Infinity (Crawley, UK) linear accelerator. Treatment verification was done using cone beam computed tomography $(\mathrm{CBCT})$ daily for the first 3 fractions followed by twice weekly for the rest of the fractions.

Patients were evaluated weekly for acute toxicities and graded as per Common Terminology Criteria for Adverse Events (CTCAE) version 4.03. Acute toxicities evaluated were: diarrhoea, proctitis, anal pain, urinary frequency, urinary urgency, urinary incontinence, cystitis and radiation dermatitis. Post-treatment follow-up was done every month for 3 months and once every three months thereafter. Follow-up cystoscopy and urine cytology was performed every $3^{\text {rd }}$ month for 2 years, every 6 months for the next 2 years and annually thereafter. CECT thorax, abdomen and pelvis was performed once every 6 months for the first 2 years and annually thereafter to evaluate the status of locoregional disease. Patients were also advised
Table 3. Highest grade acute radiotherapy toxicities as per Common Terminology Criteria for Adverse Events (CTCAE) version 4.03

\begin{tabular}{lccc|} 
Parameter & Grade 1 & Grade 2 & Grade 3 \\
Proctitis & $17(68)$ & $3(12)$ & $1(4)$ \\
Rectal pain & $8(32)$ & $4(16)$ & 0 \\
Radiation dermatitis & $3(12)$ & 0 & 0 \\
Cystitis & $15(60)$ & $1(4)$ & $2(8)$ \\
Urinary frequency & $21(84)$ & $3(12)$ & $1(4)$ \\
Diarrhoea & $14(56)$ & $2(8)$ & $3(12)$ \\
Anaemia & 0 & $5(20)$ & $1(4)$ \\
Neutropenia & $2(8)$ & $4(16)$ & $1(4)$
\end{tabular}

Data are given as $n$ (\%)

to have kidney function tests including serum electrolytes at each visit.

\section{Statistical analysis}

Statistical analysis was done with SPSS using software version 20. Mean and standard deviation were estimates of quantitative data. Local control was defined as no evidence of tumour at the primary site based on clinical, cystoscopic and/or radiographic findings. Bladder preservation rates were evaluated at the time of the last follow-up and were defined as the percentage of patients having an intact functional bladder. Overall survival (OS) was calculated from the date of registration to the date of death from any cause. Progression-free survival (PFS) was evaluated from the date of registration to the date of disease progression. Survival rates were estimated using the Kaplan-Meier method.

Table 4. Comparative analysis of various studies using intensity-modulated radiotherapy (IMRT) in bladder

\begin{tabular}{|c|c|c|c|c|c|c|c|c|}
\hline Study & $\begin{array}{c}\text { Patient } \\
\text { population }\end{array}$ & $\begin{array}{c}\text { RT } \\
\text { techniques }\end{array}$ & RT dose & $\begin{array}{c}\text { Concurrent } \\
\text { chemotherapy }\end{array}$ & DFS/LRC & $\begin{array}{l}\text { Overall } \\
\text { survival }\end{array}$ & GI toxicities & GU toxicities \\
\hline $\begin{array}{l}\text { Turgeon } \\
\text { et al. } \\
{[31]}\end{array}$ & $\begin{array}{c}\text { T2-T3NOMO } \\
(n=24)\end{array}$ & $\begin{array}{l}\text { IMRT hypo- } \\
\text { fractionated }\end{array}$ & $\begin{array}{c}50 \mathrm{~Gy} / 20 \# \text { to } \\
\text { bladder PTV } \\
40 \mathrm{~Gy} / 20 \# \text { to } \\
\text { nodal PTV }\end{array}$ & $\begin{array}{c}\text { Cisplatin } 40 \\
\mathrm{mg} / \mathrm{m}^{2}\end{array}$ & $\begin{array}{c}3 \text { year } \\
\text { DFS: } 75 \%\end{array}$ & $\begin{array}{l}3 \text { year } \\
\text { OS: } 61 \%\end{array}$ & $\begin{array}{c}\text { Grade } 3: 4 \% \\
\text { Grade 2: } \\
\text { 29\% } \\
\text { Grade 1: } \\
50 \%\end{array}$ & $\begin{array}{l}\text { Grade } 3: 4 \% \\
\text { Grade 2: } 29 \% \\
\text { Grade 1: } 41 \%\end{array}$ \\
\hline $\begin{array}{l}\text { Hsieh } \\
\text { et al. } \\
{[12]}\end{array}$ & $\begin{array}{c}\text { T2 to T4 or } \\
\text { high-risk } \\
\text { T1NOMO } \\
(n=19)\end{array}$ & IMRT & $64.8 \mathrm{~Gy} / 36 \#$ & $\begin{array}{c}\text { Cisplatin } 35 \\
\mathrm{mg} / \mathrm{m}^{2}\end{array}$ & $\begin{array}{l}2 \text { year } \\
\text { LRPFS: } \\
84.9 \%\end{array}$ & $\begin{array}{c}2 \text { year } \\
\text { OS: } \\
33.2 \%\end{array}$ & $\begin{array}{l}\geq \text { grade } 2: \\
5 \%\end{array}$ & $\begin{array}{c}\geq \text { grade } 2: \\
0 \%\end{array}$ \\
\hline $\begin{array}{l}\text { Whalley } \\
\text { et al. } \\
{[30]}\end{array}$ & $\begin{array}{c}\text { T2-T4NOMO } \\
(n=28)\end{array}$ & IMRT & $\begin{array}{c}66 \text { Gy/30\# } \\
(n=21) \text { or } \\
55 \text { Gy in } 20 \# \\
(n=7)\end{array}$ & $\begin{array}{c}\text { Cisplatin } 35 \\
\mathrm{mg} / \mathrm{m}^{2}\end{array}$ & $\begin{array}{c}90 \% \\
\text { CTRT, } \\
86 \% \\
\text { RT alone }\end{array}$ & $\begin{array}{c}100 \% \\
\text { CTRT, } \\
69 \% \\
\text { RT alone }\end{array}$ & $\begin{array}{l}\geq \text { grade } 2: \\
21 \%\end{array}$ & $\begin{array}{l}\geq \text { grade } 2: \\
21 \%\end{array}$ \\
\hline $\begin{array}{l}\text { Murthy } \\
\text { et al. } \\
{[11]}\end{array}$ & $\begin{array}{c}\text { T1-T4NOMO } \\
\text { TCC } \\
(n=44)\end{array}$ & $\begin{array}{c}\text { IMRT-SIB } \\
\text { plan of the } \\
\text { day }\end{array}$ & $\begin{array}{c}\text { 64Gy/32\# to } \\
\text { bladder PTV } \\
55 G y / 32 \# \text { to } \\
\text { nodal PTV }\end{array}$ & $\begin{array}{c}\text { Cisplatin } 30 \\
\mathrm{mg} / \mathrm{m}^{2}\end{array}$ & $\begin{array}{c}\text { 3-year } \\
\text { LRC: } 78 \%\end{array}$ & $\begin{array}{c}3 \text { year } \\
\text { OS: } 67 \%\end{array}$ & $\begin{array}{c}\text { Grade 2: } \\
27 \%\end{array}$ & $\begin{array}{c}\text { Acute grade } \\
\text { 3: } 11 \% \\
\text { Acute grade } \\
\text { 2: } 34 \%\end{array}$ \\
\hline $\begin{array}{l}\text { Our } \\
\text { study }\end{array}$ & T2-4NOMO & IMRT-SIB & $\begin{array}{c}60 \text { Gy/30\# to } \\
\text { bladder PTV } \\
54 \text { Gy/30\# to } \\
\text { nodal PTV }\end{array}$ & $\begin{array}{c}\text { Cisplatin } 40 \\
\mathrm{mg} / \mathrm{m}^{2}\end{array}$ & $\begin{array}{l}\text { 3-year } \\
\text { PFS: } \\
65.6 \%\end{array}$ & $\begin{array}{c}\text { 3-year } \\
\text { OS: } \\
81.2 \%\end{array}$ & $\begin{array}{c}\geq \text { grade } 2 \text { : } \\
20 \%\end{array}$ & $\begin{array}{c}\geq \text { grade } 2: \\
16 \%\end{array}$ \\
\hline
\end{tabular}




\section{Results}

29 patients were enrolled in the study during August 2015 to November 2016. Out of these, 1 patient developed bone metastasis during RT, 2 patients defaulted during RT and one patient developed hydroureteronephrosis due to bladder obstruction even before the start of RT and these 4 patients were excluded. 25 patients who completed the treatment as per protocol and followed up thereafter were included in this final analysis. The baseline patient characteristics of these patients are presented in Table 2 .

Median RT duration was 45 days (range 44-51 days). $3 / 25$ (12\%) patients required RT interruption for $>3$ days (1 patient had 5 days interruption due to grade 3 diarrhoea and 2 patients had $>7$ days interruption due to leukopenia). The median number of concurrent cisplatin cycle was 5 (range 3-6 cycles). Median RT dose delivered to PTV-P was 60 Gy and to PTV-N was 54 Gy.

200 CBCT images based on bony landmark registrations were done in 25 patients (median 8 per patient). The median shifts in supero-inferior, antero-posterior and lateral (left-right) directions were $5.3 \pm 2.2,4.2 \pm 1.8$ and 1.1 $\pm 0.7 \mathrm{~mm}$ respectively. A PTV margin of $1 \mathrm{~cm}$ as used in our study encompassed the daily variations in all CBCT data.

Acute RT toxicities are tabulated in Table 4. Acute grade $4 \mathrm{Gl}$ or GU toxicity was not reported in any of the patients. $1 / 25$ patient had grade 3 febrile neutropenia and grade 3 diarrhoea for which the patient needed hospitalization. Grade 3 anaemia was observed in 1 patient requiring blood transfusion. No patient experienced thrombocytopenia.

Median follow-up was 34 months (10-45 months). 6 patients died in this period. Among them, 4 patients had disease progression (2 local progression, 1 patient brain metastasis and 1 had bone and liver metastasis). Renal failure was the cause of death in 2 patients and 2 patients died due to disease progression. 2 patients died due to myocardial infarction and were disease free until the last visit. 3-year progression-free survival, overall survival and distant metastasis-free survival were $65.6 \%, 81.2 \%$ and $90.5 \%$ respectively. Bladder preservation rate at 3 years was $68 \%$.

\section{Discussion}

The RT dose used for TMT is in the range 60-64 Gy in various studies $[18,19]$. Two TROG studies have demonstrated tolerability of low dose weekly cisplatin with minimal acute toxicity [20]. James et al. in a randomized trial used fluorouracil $\left(500 \mathrm{mg} / \mathrm{m}^{2}\right)$ during fractions $1-5$ and 16-20 of RT and mitomycin C $\left(12 \mathrm{mg} / \mathrm{m}^{2}\right)$ on day 1 . However, grade 3 and 4 acute toxicity reported in this study was about 36\%. Among IMRT studies, Murthy et al. [11] used concurrent cisplatin $30 \mathrm{mg} / \mathrm{m}^{2}$ weekly. In our study, we used 60 Gy for the primary PTV with injection of cisplatin $40 \mathrm{mg} / \mathrm{m}^{2}$ weekly as the concurrent chemotherapy regimen.

In our study, contouring was done as per Australian \& New Zealand faculty of Radiation Oncology Genito-Urinary Group 2011 consensus guidelines [14, 15]. Studies are ongoing to define the inclusion of whole or partial bladder for CTV in hypo-fractionated RT in bladder [21]. Prostatic involvement by bladder cancer is not uncommon and it increases with multifocal tumour, bladder trigone tumours and presence of carcinoma in situ $[22,23]$. MIBC with urethral involvement has a high propensity to involve the vaginal wall; thus these sites of potential spread need to be included in the CTV $[15,24]$. Elective lymph node RT in MIBC has remained controversial. In radical cystectomy series with extensive lymph node dissection, the lymph node positivity rate was about $25 \%$. Various studies have demonstrated that an extended lymphadenectomy and higher number of lymph nodes identified in the pathologic specimen are associated with improved locoregional control and overall survival $[25,26]$. Further, $T$ stage $\geq T 3$ and presence of lymph vascular invasion (LVI) in preoperative biopsy have been associated with a higher number of pelvic lymph nodes involved [27]. Based on the cystectomy series data, we decided to treat internal, external iliac, presacral and obturator groups and delivered 54 Gy in 30 fractions to the elective nodal volumes. Other studies have also used this dose fractionation schedule $[28,29]$. We did not observe any nodal failures in our patients. However, our study lacks a sufficient sample size to meaningfully draw any conclusion on this aspect of management.

There are very few clinical studies addressing the impact of IMRT/VMAT on the locoregional control and toxicity in management of MIBC. Whally et al. evaluated the role of IMRT in MIBC [30]. However, this study included patients undergoing both RT alone and CRT, different RT fractionations were used and about $32 \%$ had previous BCG treatment. Other studies pertaining to IMRT in bladder cancers such as that of Turgeon et al. [31] used hypo-fractionated RT and neither Turgeon et al. [31] nor Hsieh et al. [12] used any image guidance, making treatment uncertainties a major reason for concern. Murthy et al. [11] evaluated the "plan of the day" approach with differential PTV margins and IGRT. However, even their results were diluted by inclusion of patients receiving neoadjuvant chemotherapy. Thus, the strength of our study lies in inclusion of a naive group of patients without any previous BCG therapy, without hydronephrosis and prospectively treating them with VMAT along with image guidance without the use of neo-adjuvant chemotherapy.

Acute $\mathrm{Gl}$ and GU toxicities have been the biggest impediment in RT of bladder cancer. Various IMRT studies have reported acute $\mathrm{Gl}$ toxicity $\geq$ grade 2 being $21-38 \%$ and acute GU toxicity $\geq$ grade 2 ranging from 21 to $50 \%$. The toxicity profile in these studies has been shown to be dependent on whether concurrent chemotherapy was used or not. Studies have demonstrated that use of IMRT has resulted in a higher degree of small bowel sparing. Treatment interruptions due to acute GI or GU toxicities are seen in as many as $11 \%$ of patients (20) treated using conventional RT. A comparative table depicting toxicities and outcomes is presented in Table 4.

Complete response achieved with various IMRT series has been at par with the conventional RT era. Most studies report $87-90 \%$ CR rates with RT alone and 90-100\% CR rates with use of the CRT regimen. The bladder preservation rate reported in the study by Murthy et al. [11] was $83 \%$ at 3 years; in our study it was $68 \%$ at 3 years. Higher 
rates of bladder preservation in the Murthy et al. (11) study may be due to use of neo-adjuvant chemotherapy. The disease-free survival rates and OS rates have been variable. Most studies have reported 2-year locoregional control rates ranging from $78 \%$ to $90 \%$ and 2 -year OS ranging from $26 \%$ to $69 \%$. 3-year OS and PFS in our study were $65.6 \%$ and $81.2 \%$ respectively and comparable with existing literature (Table 4). Since bladder cancer is a disease of the elderly and OS data have more contributing factors such as comorbidities at this age, we believe that $2-3$ year disease-free survival rates are a more reliable endpoint for efficacy of IMRT technique.

The patients included in our study were those with a complete TURBT, no carcinoma in situ, no hydronephrosis, T2-T4 disease with node negative status, aged 18-80 years and unifocal tumours. These patients were mostly ideal candidates for a TMT approach and the patients were also not fairly those who were deemed unsuitable for surgery but those who were unwilling to undergo a radical cystectomy. There has not been a phase III randomized controlled trial directly comparing radical cystectomy with TMT. An attempt to derive comparative outcome analysis between radical cystectomy and trimodality therapy has been made by several authors. However, these suffer from many confounders and existence of imbalance between patient and tumour factors. A propensity score analysis by Kulkarni et al. showed no difference in disease-specific survival in two arms and the rate of salvage cystectomy in the TMT arm was 10\% [4]. The long-term outcome reported by the Massachusetts General Hospital, Boston group suggested excellent 10-year disease-specific survival of $59 \%$ and overall survival of $39 \%$. The 5 -year salvage cystectomy rate was 16\% in patients treated between 2005 and 2013 [32]. Systemic dissemination remains one of the predominant failure patterns in patients treated with either radical cystectomy or TMT. To combat this, some authors have also suggested incorporation of neo-adjuvant chemotherapy with the TMT approach, and this needs to be validated in future clinical trials to further improve the outcome of patients treated with the TMT approach [33].

The follow-up of patients with bladder cancer could be tricky and is mostly guided by consensus guidelines rather than evidence-based practice. Particularly, the interpretation of cystoscopy after definitive TMT may be difficult. After definitive trimodality therapy of muscle invasive bladder cancer, urine cytology, liver and renal function tests are recommended every 3-6 months for the first 2 years. Imaging of chest, abdomen and pelvis is recommended every 3-6 months for 2 years. Random biopsies are also recommended by ESMO guideline in these patients at every 3-6-month interval for 2 years [34]. However, random biopsies are not recommended during follow-up by NCCN guidelines [35]. We used cystoscopy, urine cytology, imaging and kidney function tests including serum electrolytes for follow-up of patients as mentioned in the materials and methods section. We did not use random biopsies in our cohort of patients during follow-up as we had excluded patients with multifocal disease and those with carcinoma in situ disease.
The strength of our study lies in the inclusion of a relatively uniform group of patients, and exclusion of patients with hydronephrosis, previous BCG therapy or any neoadjuvant chemotherapy. All our patients received CRT as per protocol along with image guidance with minimal treatment interruption, thus implying good compliance. Properly selected patients with strict compliance, detailed toxicity reporting and complete follow-up data provide value to our study. However, our study had inherent limitations of a relatively small patient number and relatively short follow-up.

\section{Conclusions}

VMAT with concurrent cisplatin-based chemotherapy in MIBC patients unsuitable/unwilling for surgery yielded a 3-year bladder preservation rate of $68 \%$ in our study and is associated with acceptable acute radiation morbidities.

\section{The authors declare no conflict of interest.}

\section{References}

1. Bray F, Ferlay J, Soerjomataram I, Siegel RL, Torre LA, Jemal A. Global cancer statistics 2018: GLOBOCAN estimates of incidence and mortality worldwide for 36 cancers in 185 countries. CA Cancer I Clin 2018; 68: 394-424.

2. Benner C, Greenberg M, Shepard N, Meng MV, Rabow MW. The Natural History of Symptoms and Distress in Patients and Families Following Cystectomy for Treatment of Muscle Invasive Bladder Cancer. J Urol 2014; 191: 937-942.

3. Henningsohn L. Quality of life after therapy for muscle-invasive bladder cancer. Curr Opin Urol 2006; 16: 356-360.

4. Kulkarni GS, Hermanns T, Wei Y, et al. Propensity Score Analysis of Radical Cystectomy Versus Bladder-Sparing Trimodal Therapy in the Setting of a Multidisciplinary Bladder Cancer Clinic. J Clin Oncol 2017; 35: 2299-2305.

5. Gray PJ, Fedewa SA, Shipley WU, et al. Use of Potentially Curative Therapies for Muscle-invasive Bladder Cancer in the United States: Results from the National Cancer Data Base. Eur Urol 2013; 63: 823-829.

6. James ND, Hussain SA, Hall E, et al. Radiotherapy with or without Chemotherapy in Muscle-Invasive Bladder Cancer. N Engl J Med 2012; 366: 1477-1488.

7. Fahmy O, Khairul-Asri MG, Schubert T, et al. A systematic review and meta-analysis on the oncological long-term outcomes after trimodality therapy and radical cystectomy with or without neoadjuvant chemotherapy for muscle-invasive bladder cancer. Urol Oncol Semin Orig Investig 2018; 36: 43-53.

8. Coppin CM, Gospodarowicz MK, James K, et al. Improved local control of invasive bladder cancer by concurrent cisplatin and preoperative or definitive radiation. The National Cancer Institute of Canada Clinical Trials Group. J Clin Oncol 1996; 14: 2901-2907.

9. James ND, Hussain SA, Hall E, et al. Radiotherapy with or without Chemotherapy in Muscle-Invasive Bladder Cancer. N Engl J Med 2012; 366: 1477-1488.

10. Foroudi F, Wilson L, Bressel M, et al. A dosimetric comparison of 3D conformal vs intensity modulated vs volumetric arc radiation therapy for muscle invasive bladder cancer. Radiat Oncol 2012; 7: 111.

11. Murthy V, Masodkar R, Kalyani N, et al. Clinical Outcomes With Dose-Escalated Adaptive Radiation Therapy for Urinary Bladder Cancer: A Prospective Study. Int J Radiat Oncol 2016; 94: 60-66.

12. Hsieh C-H, Chung S-D, Chan P-H, et al. Intensity modulated radiotherapy for elderly bladder cancer patients. Radiat Oncol 2011; 6: 75.

13. Edge S, Byrd DR, Compton CC, Fritz AG, Greene FL, Trotti A. AJCC Cancer Staging Manual, $7^{\text {th }}$ ed. Springer 2009. 
14. Hindson BR, Turner SL, Millar JL, et al. Australian \& New Zealand Faculty of Radiation Oncology Genito-Urinary Group: 2011 consensus guidelines for curative radiotherapy for urothelial carcinoma of the bladder. J Med Imaging Radiat Oncol 2012; 56: 18-30.

15. Gultekin M, Sari SY, Hurmuz P, Yazici G, Akyol F, Ozyigit G. Target Volume Delineation Target Volume Delineation for bladder cancer Guidelines in Bladder Cancer. In: Principles and Practice of Urooncology. Springer International Publishing, Cham 2017: 75-84.

16. Prostate Pelvic Lymph Nodes. Available from: https://www.rtog. org/CoreLab/ContouringAtlases/ProstatePelvicLymphNodes.aspx (access: 9 May 2019).

17. Gay HA, Barthold HJ, O'Meara E, et al. Pelvic normal tissue contouring guidelines for radiation therapy: a Radiation Therapy Oncology Group consensus panel atlas. Int J Radiat Oncol Biol Phys 2012; 83: e353-362.

18. Sengel $\varnothing \vee \mathrm{L}$, von der Maase H. Radiotherapy in bladder cancer. Radiother Oncol 1999; 52: 1-14.

19. Nowak-Sadzikowska J, Skóra T, Szyszka-Charewicz B, Jakubowicz J. Muscle-invasive bladder cancer treated with TURB followed by concomitant boost with small reduction of radiotherapy field with or without of chemotherapy. Reports Pract Oncol Radiother 2016; 21: 31-36

20. George L, Bladou F, Bardou VJ, et al. Clinical outcome in patients with locally advanced bladder carcinoma treated with conserva tive multimodality therapy. Urology 2004; 64: 488-493.

21. Kang JJ, Steinberg ML, Kupelian P, Alexander S, King CR. Whole Versus Partial Bladder Radiation. Am J Clin Oncol 2015; 41: 1.

22. Shen SS, Lerner SP, Muezzinoglu B, Truong LD, Amiel G, Wheeler TM. Prostatic involvement by transitional cell carcinoma in patients with bladder cancer and its prognostic significance. Hum Pathol 2006; 37: 726-734.

23. Richards KA, Parks GE, Badlani GH, Kader AK, Hemal AK, Pettus JA. Developing Selection Criteria for Prostate-sparing Cystectomy: A Review of Cystoprostatectomy Specimens. Urology 2010; 75: 1116-1120.

24. Stein JP, Penson DF, Wu SD, Skinner DG. Pathological Guidelines for Orthotopic Urinary Diversion in Women With Bladder Cancer: A Review of the Literature. J Urol 2007; 178: 756-760.

25. Baumann BC, Guzzo TJ, He J, et al. A Novel Risk Stratification to Predict Local-Regional Failures in Urothelial Carcinoma of the Bladder After Radical Cystectomy. Int J Radiat Oncol 2013; 85: 81-88.

26. Tarin TV, Power NE, Ehdaie B, et al. Lymph Node-Positive Bladder Cancer Treated With Radical Cystectomy and Lymphadenectomy: Effect of the Level of Node Positivity. Eur Urol 2012; 61: 1025-1030.

27. Goldsmith B, Baumann BC, He J, et al. Occult Pelvic Lymph Node Involvement in Bladder Cancer: Implications for Definitive Radiation. Int J Radiat Oncol 2014; 88: 603-610.

28. Tunio MA, Hashmi A, Qayyum A, Mohsin R, Zaeem A. Whole-Pelvis or Bladder-Only Chemoradiation for Lymph Node-Negative Invasive Bladder Cancer: Single-Institution Experience. Int J Radiat Oncol 2012; 82: e457-462

29. Foroudi F, Wilson L, Bressel M, et al. A dosimetric comparison of 3D conformal vs intensity modulated vs volumetric arc radiation ther apy for muscle invasive bladder cancer. Radiat Oncol 2012; 7: 111

30. Whalley D, Caine H, McCloud P, Guo L, Kneebone A, Eade T. Promising results with image guided intensity modulated radiotherapy for muscle invasive bladder cancer. Radiat Oncol 2015; 10: 205.

31. Turgeon GA, Souhami L, Cury FL, Faria SL, Duclos M, Sturgeon J, Kassouf W. Hypofractionated intensity modulated radiation therapy in combined modality treatment for bladder preservation in elderly patients with invasive bladder cancer. Int Jour Radiat Oncol Bio Phy 2014; 88: 326-331.

32. Giacalone NJ, Shipley WU, Clayman RH, et al. Long-term Outcomes After Bladder preserving Tri-modality Therapy for Patients with Muscle-invasive Bladder Cancer: An Updated Analysis of the Massachusetts General Hospital Experience. Eur Urol 2017; 71: 952-960.

33. Winquist E, Booth CM. Trimodality Therapy for Muscle-Invasive Bladder Cancer: Concurrent Chemotherapy is Not Enough. J Clin Oncol 2020; 38: 2709-2711.

34. Bellmunt J, Orsola A, Leow J, et al. Bladder cancer: ESMO Practice Guidelines for diagnosis, treatment and follow-up. Ann Oncol. 2014; 25 (Suppl 3): iii40-iii48.
35. Flaig TW, Spiess PE, Agarwal N, et al. Bladder Cancer, Version 3.2020, NCCN Clinical Practice Guidelines in Oncology. J Natl Compr Canc Netw 2020; 18: 329-354.

\section{Address for correspondence}

\section{Ajeet K. Gandhi}

Department of Radiation Oncology

Dr Ram Manohar Lohia Institute of Medical Sciences Vibhuti Khand, Gomti Nagar

Lucknow 226010, India

e-mail: ajeetgandhi23@gmail.com

Submitted: 25.07 .2020

Accepted: 25.08 .2020 